\title{
Early Physiotherapy Does Not Influence Seroma Formation among Patients Undergoing Breast Surgery- A Prospective Randomized Study
}

\author{
Swapnali Mandlik', Tejashri Deshpande ${ }^{1}$, Sirshendu Roy', Supriya Palwe' ${ }^{1}$, Shrikant Suryavanshi', Rajnish Nagarkar ${ }^{1}$ \\ 'Department of Physiotherapy, HCG Manavata Cancer Center, Off Nashik Expressway, Near Mylan Circle, Nashik- 422 002, India.
}

\section{Abstract}

Background: Seroma formation is a common side-effect rather than a complication among breast cancer patients undergoing mastectomy and axillary dissection. Early physiotherapy among such patients is hypothesized to decrease the risk of seroma formation. The objective of the study was to assess the impact of early physiotherapy on seroma formation, shoulder disability/mobility and functional capacity, pain, post-operative drain removal, and lymphedema. Subjects and Methods: A total of 103 patients were enrolled in the prospective randomized study. All patients were admitted at HCG Manavata Cancer Centre, Nashik, India. The study involved 41 patients who had undergone breast conservative surgery and 62 patients who had undergone modified radical mastectomy. Patients were randomly assigned to 'early physiotherapy' or 'delayed physiotherapy' group. Results: A total of eight patients in the 'early physiotherapy' group and fourteen patients in the 'delayed physiotherapy' group developed seroma. No statistical significance was noted in context to seorma formation and physiotherapy as an intervention. Conclusion: Early physiotherapy does not influcneseroma formation among patients who undergo breast surgery with axillary dissection. However, early physiotherapy helped in improving shoulder disability, mobility, and functional capacity. In context to the early post-operative period, physiotherapy has reduced pain among patients. There is a need for large multi-center trials to assess the potential of early physiotherapy in reducing or preventing seroma among breast cancer patients.

Keywords: Breast surgery, Seroma, Physiotherapy, Shoulder exercises.

Corresponding Author: Dr. Swapnali Mandlik, Department of Physiotherapy, HCG Manavata Cancer Center, Off Nashik Expressway, Near Mylan Circle, Nashik- 422 002, India.

Received: June 2019

Accepted: June 2019

\section{Introduction}

Breast cancer has become a leading cause of death among women worldwide over the past 30 years. ${ }^{[1]}$ Breast cancer has significantly contributed to over cancer surgical load. Depending on the disease stage, the surgical approach for breast cancer may include breast conservation therapy (BCT) or mastectomy with or without axillary dissection. Seroma formation is the most common post-surgical complication observed in patients undergoing mastectomy and/or axillary surgery. The incidence of seroma formation ranges from $3 \%$ to $85 \%$. $^{[2]}$

Seroma formation has become a common complication that it is now believed to be a side-effect of breast surgery. Seroma-related morbidity as extended drainage is not only inconvenient to the patient but also extensively affects overall treatment outcomes. Seroma formation may delay adjuvant therapy and increases overall risk of infection. ${ }^{[2]}$ In cases of persistent and long-lasting seroma, a reoperation may be considered. ${ }^{[3]}$

Seroma formation has been associated with an increased risk of delayed wound healing, wound hematoma, and lymphedema. Seromas may not necessarily be life threatening but could lead to several morbidities such as wound dehiscence, flap necrosis, predisposition to sepsis, impaired shoulder function, multiple physician visits, and prolonged recovery period. These comorbidities may delay the commencement of adjuvant therapy. ${ }^{[4,5]}$ Seroma formation is often observed on the 7th day post-surgery while it is reaches its peak on the 8th day until the 16th day wherein it gradually decreases thereafter. ${ }^{[6]}$

It is important to estimate individual risk of seroma formation. The role of early physiotherapy may help in influencing or preventing seroma formation. However, the use of physiotherapy on overall incidence of post-surgical complications is unclear. The aim of the study is to assess the impact or role of physiotherapy among patients undergoing breast cancer surgery.

\section{Subjects and Methods}

A total of 103 patients were enrolled in the prospective randomized study. All patients were admitted at HCG Manavata Cancer Centre, Nashik, India. The study involved 41 patients who had undergone breast conservative surgery and 62 patients who had undergone modified radical mastectomy. All cases involved axilla dissection. All surgeries were performed at a single site.

In all cases a closed drainage system was used. The system comprised of a plastic bad attached to a drainage tube. The 
drainage tube was brought out through a separate skin incision. Individual bags were emptied while the drainage volume was measured every 24 hours. The drain was removed as per surgeon's discretion, specifically when the drainage volume was less than $50 \mathrm{ml}$ within the 24 hours. Patients were randomly assigned to treatment groups, i.e. 50 were assigned to early physiotherapy and 53 were assigned to delayed physiotherapy group.

In the 'early treatment' group, the physiotherapist commenced exercises on the first operative day. The patients were treated with active-assisted shoulder exercises progressive to active shoulder exercises. The patients were instructed and trained to do active shoulder exercises. The objective of the exercises was to regain full range of motion of affected side's shoulder joint. The target areas include shoulder anterior flexion, rotation, and abduction. Each patient was advised to perform the exercises five times a day (10 repetitions each).

In contrast, the 'delayed treatment' group involved the same exercise regimen, except that they were performed on postoperative day 8 with due discretion of the surgeon and the physiotherapist. All the patients were seen by the surgeon and the physiotherapist at the outpatient department of the hospital.

All patients were closely monitored for drain volume, removal, seroma formation, and aspiration by respective surgeons. All patients were observed prospectively for seroma formation and aspiration. Seroma formation was clinically defined as apparent swelling in the subcutaneous space under the flaps or within the axilla.

The first day seroma was observed post-operatively was noted. The diagnosis of sermoa was confirmed by aspiration. Drain removal was performed when the drainage output was reduced to a minimum of $25 \mathrm{ml}$ in a 24-hour interval. The duration of drain removal was also observed.

The post-operative on which days Seroma was first observed was also noted. The diagnosis was confirmed by aspiration. Drain removal was done when the drainage output reduced to a minimal amount approximately below $25 \mathrm{ml} / 24 \mathrm{hr}$ or duration of drain removal was also noted. Seroma was considered to be significant when the total volume of fluid exceeded $20 \mathrm{ml}$. The fluid was aspirated beneath the skin flap or drain site.

Patients were assessed for pain, shoulder anterior flexion/abduction, and lymphedema by the physiotherapist on the 8th post-surgery in both groups. These are common complications of breast surgery and thus the physiotherapist assessed these factors.

The physiotherapist used a goniometer to assess shoulder range of motion, i.e. shoulder anterior flexion and abduction. The visual analogue scale and girth measurement was used to assess pain and lymphedema respectively.

After collection of all observations, statistical analysis was performed. The incidence of seroma in the study population was calculated. Key variables such as post-operative drain removal day, age, should range of motion (abduction and anterior flexion), lymphedema, and pain.

\section{Results}

As per the observations, a total of 22 patients had developed seroma. A total of 8 patients were from the 'early physiotherapy' group while 14 patients were from the 'delayed physiotherapy' group. The overall incidence of seroma formation was not statistically significant [Table 1]. In context to age, there was no statistical significance in seroma formation. The mean age was 49.13 in the 'early treatment' group and '50.75' in the 'delayed treatment' group [Table 2].

In context to drain removal, the mean post-operative day was 14.5 in 'early treatment' group and 14.38 in the 'delayed treatment' group. The standard deviation was 3.94 and 4.54 in the 'early treatment' and 'delayed treatment' group respectively [Table 3]. Thus, there was no statistical significance in context to physiotherapy time on overall post-operative drain removal time.

In context to shoulder mobility, the mean shoulder anterior flexion value was 170.18 and 106.73 for early and delayed treatment groups respectively. The P-value was 0.00 . The shoulder anterior flexion range of motion was restricted in the 'delayed treatment' group [Table 4]. In context to shoulder abduction, the mean values were 167.73 and 99.18 in the 'early treatment' and 'delayed treatment' groups respectively [Table 5]. The shoulder abduction range of motion was restricted in the 'delayed treatment group'.

In context to pain, the mean values were 2.47 and 8 in the 'early treatment' and 'delayed treatment' groups respectively. The standard deviation was 1.72 and 1.47 respectively [Table 6]. There was clinical and statistical significance in context to the pain score which was higher in the 'delayed treatment' group.

A total of four patients had developed lymphedema within a span of one year. Each group, i.e. 'early treatment' and 'delayed treatment' groups had two patients who had developed mild to moderate lymphedema. However, there was no statistical significance in context to incidence of lymphedema in both groups [Table 7].

Table 1:Seroma formation in study groups.
\begin{tabular}{|l|l|l|}
\hline Seroma & Early Physiotherapy & Delayed Physiotherapy \\
\hline Yes & 8 & 14 \\
\hline No & 45 & 35 \\
\hline P-value & 0.0983 & \\
\hline Significance & Not Significant \\
\hline
\end{tabular}

Table 2: Age-wise distribution in early and delayed physiotherapy groups

\begin{tabular}{|l|l|l|}
\hline Age & $\begin{array}{l}\text { Early } \\
\text { Physiotherapy }\end{array}$ & Delayed Physiotherapy \\
\hline Mean & 49.13207547 & 50.75510204 \\
\hline $\begin{array}{l}\text { Standard } \\
\text { Deviation }\end{array}$ & 13.89941578 & 12.72879055 \\
\hline P-value & 0.5336 & \\
\hline Significance & Not Significant \\
\hline
\end{tabular}


Table 3: Postoperative drain removal day in early and delayed physiotherapy groups

\begin{tabular}{|l|l|l|}
\hline $\begin{array}{l}\text { Postoperative } \\
\text { Day Drain } \\
\text { Removal }\end{array}$ & $\begin{array}{l}\text { Early } \\
\text { Physiotherapy }\end{array}$ & Delayed Physiotherapy \\
\hline Mean & 14.15384615 & 14.3877551 \\
\hline $\begin{array}{l}\text { Standard } \\
\text { Deviation }\end{array}$ & 3.947620854 & 4.540632879 \\
\hline P-value & 782 & \\
\hline Significance & Not Significant \\
\hline
\end{tabular}

Table 4: Shoulder anterior flexion in early and delayed physiotherapy groups

\begin{tabular}{|l|l|l|}
\hline $\begin{array}{l}\text { Shoulder } \\
\text { Anterior } \\
\text { Flexion }\end{array}$ & $\begin{array}{l}\text { Early } \\
\text { Physiotherapy }\end{array}$ & Delayed Physiotherapy \\
\hline Mean & 170.1886792 & 106.7346939 \\
\hline $\begin{array}{l}\text { Standard } \\
\text { Deviation }\end{array}$ & 17.4852208 & 22.48960455 \\
\hline pvalue & 0.0000 & \\
\hline Significance & $<0.0001$ & \\
\hline
\end{tabular}

Table 5: Shoulder abduction in early and delayed physiotherapy groups

\begin{tabular}{|l|l|l|}
\hline $\begin{array}{l}\text { Shoulder } \\
\text { Abduction }\end{array}$ & $\begin{array}{l}\text { Early } \\
\text { Physiotherapy }\end{array}$ & Delayed Physiotherapy \\
\hline Mean & 167.7358491 & 99.18367347 \\
\hline $\begin{array}{l}\text { Standard } \\
\text { Deviation }\end{array}$ & 20.90652359 & 14.11806389 \\
\hline P-value & 0.0000 & \\
\hline Significance & $<0.0001$ & \\
\hline
\end{tabular}

Table 6: Pain in early and delayed physiotherapy groups

\begin{tabular}{|l|l|l|}
\hline Variable-Pain & $\begin{array}{l}\text { Early } \\
\text { Physiotherapy }\end{array}$ & Delayed Physiotherapy \\
\hline Mean & 2.471698113 & 8 \\
\hline $\begin{array}{l}\text { Standard } \\
\text { Deviation }\end{array}$ & 1.727645948 & 1.471960144 \\
\hline P-value & 0.0000 & \\
\hline Significance & $<0.0001$ & \\
\hline
\end{tabular}

Table 7: Lymphedema in early and delayed physiotherapy groups

\begin{tabular}{|l|l|l|}
\hline $\begin{array}{l}\text { Variable- } \\
\text { Lymphedema }\end{array}$ & $\begin{array}{l}\text { Early } \\
\text { Physiotherapy }\end{array}$ & Delayed Physiotherapy \\
\hline Yes & 2 & 2 \\
\hline No & 51 & 47 \\
\hline pvalue & 0.9362 & \\
\hline Significance & Not Significant \\
\hline
\end{tabular}

\section{Discussion}

Seroma formation has been considered as a major sideeffect of breast and/or axillary surgery. It is an unpleasant complication that affects patient recovery and overall outcomes. Tumor-related and allied patient factors have no significant influence on seroma formation. However, body weight and body mass index are stipulated to have a favorable impact on seroma formation. ${ }^{[7]}$ In a recent study, age and obesity have been identified as critical prognostic factors that influence overall seroma formation among breast cancer patients who underwent mastectomy. ${ }^{[8]}$ In a similar study, seroma formation was associated with the type of surgery, i.e. it was more common in patients undergoing modified radical mastectomy. ${ }^{[9]}$ In context to the pathophysiology of seroma, key anatomical features such as dead space have found to contribute to overall seorma formation. ${ }^{[10]}$

Physical therapy has remained the mainstay of improving physical outcomes among patients undergoing breast cancer surgery. There is strong evidence on the impact of exercise rehabilitation in improving physical outcomes such as lymphedema and shoulder mobility. ${ }^{[1]}$ Physiotherapy has been associated to improve shoulder function among women with early breast cancer. ${ }^{[12]}$ Significant improvement in shoulder function, reduction in pain, and enhanced quality of life have been associated among patients with breast cancer after physiotherapy intervention. ${ }^{[13]}$

Although there is substantial evidence on impact of physiotherapy on shoulder function and health-related outcomes, there is paucity in data on prevention of seroma in such patients. To the best of our knowledge, this is the first of a kind study to assess and compare the effect of early versus delayed physiotherapy among breast cancer patients undergoing breast conservation surgery or modified radical mastectomy. Although the study outcomes provided no significant impact of physiotherapy on seroma formation, large multi-center trials are warranted. The valuation of seroma formation before and after physiotherapy needs further investigation.

\section{Conclusion}

Early physiotherapy does not influcne seroma formation among patients who undergo breast surgery with axillary dissection. However, early physiotherapy helped in improving shoulder disability, mobility, and functional capacity. In context to the early post-operative period, physiotherapy has reduced pain among patients. There is a need for large multi-center trials to assess the potential of early physiotherapy in reducing or preventing seroma among breast cancer patients.

\section{Acknowledgements}

We would like to thank Mr. Lyndon Fernandes for his medical writing assistance

\section{References}

1. Jemal A, Siegel R, Ward E, Hao Y, Xu J, Murray T, et al. Cancer statistics, 2008. CA Cancer J Clin. 2008;58:71-96.

2. Kumar S, Lal B, Misra MC. Post-mastectomy seroma: a new look into the aetiology of an old problem. J R CollSurgEdinb. 1995;40:292-294.

3. Stanczyk M, Grala B, Zwierowicz T, Maruszynski M. Surgical resection for persistent seroma, following modified radical mastectomy. World J SurgOncol. 2007;5:104.

4. Aitken DR, Minton JP. Complications associated with mastectomy. SurgClin North Am 1993; 63:1331-1352.

5. Chilson TR, Chan FD, Lonser RR, Wu TM, Aitken DR. Seroma prevention after modified radical mastectomy. Am Surg 1992; 58:750754.

6. Menton, MA, Roemer, VM. Seroma formation and drainage technic following mastectomy. Fortschr Med 1990: 108:350-352

7. Srivastava V, Basu S, Shukla VK. Seroma formation after breast cancer surgery: what we have learned in the last two decades. J Breast 
Cancer. 2012;15(4):373-380.

8. Zieliński J, Jaworski R, Irga N, Kruszewski JW, Jaskiewicz J. Analysis of selected factors influencing seroma formation in breast cancer patients undergoing mastectomy. Arch Med Sci. 2013;9(1):86-92.

9. Hashemi E, Kaviani A, Najafi M, Ebrahimi M, Hooshmand H, Montazeri A. Seroma formation after surgery for breast cancer. World J SurgOncol. 2004;2:44.

10. Kuroi K, Shimozuma K, Taguchi T, Imai H, Yamashiro H, Ohsumi S, Saito S. Pathophysiology of seroma in breast cancer. Breast Cancer. 2005;12(4):288-93.

11. Loh SY, Musa AN. Methods to improve rehabilitation of patients following breast cancer surgery: a review of systematic reviews. Breast Cancer (Dove Med Press). 2015;7:81-98.

12. Cave J, Jones A. Physiotherapy improves shoulder function after treatment in women with early breast cancer. Cancer Treat Rev. 2006 Aug;32(5):398-401.

13. Beurskens CH, van Uden CJ, Strobbe LJ, Oostendorp RA, Wobbes T. The efficacy of physiotherapy upon shoulder function following axillary dissection in breast cancer, a randomized controlled study. BMC Cancer. 2007;7:166.

Copyright: (C) the author(s), 2019. It is an open-access article distributed under the terms of the Creative Commons Attribution License (CC BY 4.0), which permits authors to retain ownership of the copyright for their content, and allow anyone to download, reuse, reprint, modify, distribute and/or copy the content as long as the original authors and source are cited.

How to cite this article: Mandlik S, Deshpande T, Roy S, Palwe S, Suryavanshi S, Nagarkar R. Early Physiotherapy Does Not Influence Seroma Formation among Patients Undergoing Breast Surgery- A Prospective Randomized Study. Asian J. Med. Res. 2019;8(2):MC09-MC12. DOI: dx.doi.org/10.21276/ajmr.2019.8.2.MC3

Source of Support: Nil, Conflict of Interest: None declared. 